\title{
A CONSTITUIÇÃO DE ASSOCIAÇÕES DE MULHERES DE NEGÓCIOS NA PERSPECTIVA DA TEORIA ATOR REDE
}

\section{THE CONSTITUTION OF WOMEN BUSINESS ASSOCIATIONS FROM THE PERSPECTIVE OF ACTOR NETWORK THEORY}

\author{
Hilka Vier Machado \\ Universidade do Oeste de Santa Catarina - UniCesumar - SC \\ hilkavier@yahoo.com
}

João Marcelo Crubellate

Universidade Estadual de Maringá - PR

jmcrubellate@uem.br

Maria José Barbosa de Souza

Universidade do Vale do Itajaí - Univali - SC

mjbsouza2@gmail.com

Submissão: $16 / 05 / 2017$

Aprovação: 25/05/2018

\begin{abstract}
RESUMO
Redes constituem importante recurso para empreendedores e para empreendedoras, sendo que Associações de Mulheres de Negócios no Brasil são as redes em que empreendedoras se engajam mais. A Teoria Ator Rede (TAR) busca explicar a conversão de muitos em uma unidade, o que ocorre por meio de um processo denominado Translation (LATOUR, 2008). Para essa abordagem, elementos humanos e não humanos interagem e se transformam em clamores, que estão em constante mudança. O objetivo desta pesquisa foi compreender como Associações de Mulheres de Negócios foram instituídas, a partir da abordagem TAR. Foram analisadas três Associações de Mulheres em três municípios de porte equivalente em dois Estados no sul do Brasil. Em cada caso realizou-se entrevistas abertas, do tipo narrativas, com 12 empreendedoras que contaram suas experiências nas Associações. Além disso, dados secundários foram obtidos nos arquivos das Associações Comerciais, consistindo em livros ata das reuniões das Associações de Mulheres, livros de presenças, vídeos e reportagens de jornais e revistas. O conjunto dos dados foi analisado, com suporte do software $\mathrm{N}$ vivo 9 (Qsr Nudist). Os resultados mostraram inicialmente os primeiros momentos de cada rede, seguidos da problematização, do registro e da mobilização das Associações, em busca da formação de um corpo de atores rede.
\end{abstract}

Palavras-chave: Teoria Ator Rede. Empreendedoras. Redes. 


\begin{abstract}
Networks are an important resource for entrepreneurs and for women entrepreneurs, and Business Women Associations in Brazil are the networks more women entrepreneurs engage. The Actor Network Theory (ART) tries to explain the conversion of many in a unit, which occurs through a process called translation (LATOUR, 2008). For this approach, human and non-human elements interact and become claims, which are constantly changing. The objective of this research was to understand how Business Women's Associations were established from the ART approach. Three Businesswomen Associations were analyzed in three size cities in two states in southern Brazil. For the development of each case open interviews were conducted, the narrative type, with twelve entrepreneurs who shared their experiences in the networks. In addition, secondary data were obtained from the archives of the Trade Associations, consisting of minute books of meetings of Women's Associations, attendance books, videos and articles from newspapers and magazines. All the data was analyzed with $\mathrm{N}$ live software support 9 (Qsr Nudist). The results initially showed the first moments of each network, followed by problematization, the enrollment and the mobilization of associations, seeking the formation of a body of network actors.
\end{abstract}

Keywords: Actor Network Theory. Women entrepreneurs. Networks. 


\section{INTRODUÇÃO}

A teoria do ator-rede (TAR) representa uma alternativa para o entendimento da formação de atores sociais coletivos ou, nos termos da própria teoria, macroatores. Trata-se de uma abordagem extensiva a diversos campos do saber, incluindo os estudos organizacionais (ALCADIPANI; TURETA, 2009; ALCADIPANI, HASSARD, 2010; MONTENEGRO; BULGACOV, 2014), Comunicação (CAIAFA, 2014), Contabilidade (COSTA; MORGAN, 2017; LOPES; BEUREN, 2017), Empreendedorismo (KORSGAARD, 2011; TONELLI; BRITO; ZAMBALDE, 2011), Psicologia (MÉLLO; SPINK; MENEGON, 2016), entre outros.

Para Latour (2008), uma entidade emerge de um coletivo heterogêneo, que considera a conexão entre humanos e não humanos. Para a TAR artefatos são criados e recriados, sendo importante a presença de macroatores. Estes são atores-rede que se juntam de tal modo que o conjunto é visto em forma de projetos comuns. De acordo com Feldman e Pentland (2005, p. 94): "todos se tornam macroatores na medida em que eles assumem relativamente identidades estáveis e estão reunidos por interesses particulares". Macroatores são "efeitos de redistribuições nas quais alguns falam em nome de outros que foram, assim, silenciados" (HELGESSON; KJELLBERG, 2005, p. 145).

Enquanto abordagem para compreensão da formação de coletivos, a TAR configura-se também como perspectiva analítica da formação de redes. As redes implicam no redimensionamento da ação empreendedora, na medida em que são constituídas por ações de empreendedores, mas igualmente são constituintes de ações. Em redes, o empreendedor recebe influências de variada ordem e, na dinâmica de suas ações, vê-se confrontado em seus princípios e modos de ação. Redes constituem, para empreendedoras, um recurso importante para consolidar identidades nos papéis, pois contribuem para aumentar a visibilidade (CARTER, 2001; DOWNING, 2005). No entanto, pesquisas com empreendedoras e redes são escassas. Estudos sobre redes são importantes, pois a imersão de mulheres em redes tende a ser menor do que a de homens (MANOLOVA et al., 2007); mulheres enfrentam dificuldades para constituir redes (MACHADO; JESUS, 2010) e a composição das redes é diferente, sendo que as de mulheres inclui apenas mulheres e as de homens apenas homens (CARTER, 2001).

Embora não tenham sido encontradas diferenças significativas quanto à atuação de homens e de mulheres em redes (AHL, 2004), poucos estudos abordam a formação e o surgimento de redes (HOSKISSON et al., 2011), o que é necessário para compreender as dinâmicas de redes no contexto social e empreendedor.

Nesse sentido, esta pesquisa teve como foco a constituição de Associações de Mulheres Empreendedoras, uma vez que no Brasil os Conselhos de Mulheres Empresárias, geralmente inseridos em Associações Comerciais, são redes que as empreendedoras mais recorrem. O objetivo da pesquisa foi compreender como Associações de Mulheres de Negócios foram constituídas, a partir da abordagem TAR. Foram analisadas três Associações de Mulheres de Negócios em três municípios de porte equivalente em dois Estados no sul do Brasil.

A estrutura do artigo inicia-se, após essa introdução, pela apresentação de alguns fundamentos da TAR, os quais nortearam a análise dos dados. Após descrever os procedimentos metodológicos, são apresentados os resultados da investigação. Para apresentação e análise dos dados, o texto está estruturado em duas partes principais, sendo a primeira uma breve descrição dos primeiros acontecimentos das redes e, a segunda, o processo de Translation, denominado Tradução. 


\section{FUNDAMENTOS DA TEORIA ATOR REDE}

A Teoria Ator Rede busca explicar a ação de grupos a partir de uma relação entre humanos e não humanos, "um híbrido de homens e coisas" (ESCÓSSIA; KASTRUP, 2005, p. 301). A emergência do social deriva de "associações entre humanos e não humanos" (LEMOS, 2014, p. 476). Na teoria do ator-rede, tanto humanos quanto não humanos podem assumir o papel de atores (BACHUR, 2016), pois "o social e o material são mutuamente constitutivos" (KORSGAARD, 2011, p. 665).

Atores e rede fabricam e são fabricados "em processos sequenciais de aceitação e crise" (PRIMO, 2014, p.515). Atores são actantes desde que estejam articulados em uma cadeia de relações (BACHUR, 2016). Para Latour (2008), um actante (atuante) caracteriza-se pela possibilidade de diversidade de figuração, sendo que actante pode ser qualquer coisa (humanos, máquinas ou apenas símbolos referencias para abstrações). Enquanto atores têm projetos e interesses, coisas que eles estão tentando fazer, actantes constituem "aquilo que efetua ou experimenta um ato" (GREIMAS; CORTÉS apud CZARNIAWSKA; HERNES, 2005, p. 8).

Quando um ator-rede emerge, ele age como uma unidade. A imagem de unidade "fornece a todos actantes envolvidos mais poder por meio de suas associações" (LATOUR, 1986, p. 30). A identidade de qualquer objeto, humano ou não humano, é "o resultado de relações nas quais eles entram" (KORSGAARD, 2011, p. 664). Essas relações, efeito de processos de composições e associações, "lhes conferem formas sempre provisórias" (ESCÓSSIA; KASTRUP, 2005, p. 298). Segundo Tonelli (2016, p. 379) "não pode existir ator sem que haja rede. $\mathrm{O}$ ator só é ator porque ele adquire forma, significado e identidade na rede".

O poder de agência encontra-se na rede e todos envolvidos participam de sua evolução, contudo, a atribuição de agência a objetos não anula intenções de humanos (PRIMO, 2014). Trata-se da noção de "agência distribuída", ou seja, agência distribuída entre um número amplo de atores, humanos e não humanos, ou agência com "múltiplos protagonistas" (KORSGAARD, 2011, p. 672). A agência individual reside no efeito da rede em que o ator está inserido, na medida em que "a agência individual não tem poder sem agência dos outros" (KORSGAARD, 2011, p. 669).

$\mathrm{O}$ processo se configura como conflito entre programas e antiprogramas (CZARNIAWSKA, HERNES, 2005). O programa pode ser constantemente contrariado por antiprogramas, contraposto pelas próprias contingências e, sobretudo por seus utilizadores (CAIAFA, 2014). Quando atores coletivos definem o contexto de microação de actantes humanos e não humanos, a coletividade de atores e actantes em uma rede é o que fornece o nome da teoria: ator-rede (HERNES, 2005) ou, como sugerem Czarniawska e Hernes (2005), atores em redes. Então, microatores podem configurar como macroatores. Macroatores são atores rede que se juntam, se fundem, de tal modo que "o todo é visto na forma de projetos" (FELDMAN; PENTLAND, 2005, p. 93). O termo macroatores - instituições, organizações, classes sociais, etc, (CALLON; LATOUR apud MOURITSEN; FLABSTAD, 2005, p.110) refere-se a uma metáfora, uma forma poética de fazer um ator respeitável, significante, de certa forma que "homens agem como um homem", sendo que "macroatores atingem a estabilidade e interesses" (FELDMAN; PENTLAND, 2005, p. 94). Além disso, um macroator é forte quando for bem-sucedido na mobilização de certos microatores em favor de seu projeto (MOURITSEN; FLABSTAD, 2005).

Para Hernes (2005, p.113), macroatores "recrutam, registram microatores a fim de falar em nome deles". Ao fazer isso, eles estão habilitados para confrontar outros macroatores. O processo pelo qual macroatores assumem a autoridade para agir e falar em nome de todos na rede envolve "translation" (LATOUR, 2008, p. 155). Neste sentido, deve- 
se falar do ator-rede, em vez de atores-redes, para enfatizar efeitos relacionais que recursivamente geram e reproduzem-se graças às manobras e estratégias de tradução.

Tradução (translation) "é o processo de negociação pelo qual os atores assumem a autoridade para agir e falar em nome de outros atores" (HERNES, 2005, p. 168). É tanto o movimento de uma entidade no espaço e no tempo, bem como a sua tradução de um contexto para outro - como na tradução de uma língua para outra, com a necessária transformação do significado que essa sempre implica (LATOUR, 2008). Callon e Latour (1981 apud HERNES, 2005, p. 116) definem translation como: "negociações, intrigas, cálculos, atos de persuasão e violência, graças ao qual um ator tem, ou faz com que seja atribuída a si mesmo, autoridade para falar ou agir em nome de outro ator". Tradução envolve interesses comuns, necessidade de alinhar interesses e transformação (TONELI, 2016). Na rede "as ações são atribuídas ou delegadas aos diversos actantes em um processo híbrido de traduções sucessivas" (CAIAFA, 2014, p. 599). Se a tradução é aceita, ela estabelece uma "realidade na qual algumas coisas são passiveis e legítimas, enquanto outras não são e identidades e papeis de atores envolvidos são determinados, bem como as relações entre eles". Diversas traduções podem coexistir e podem até estarem conectadas em vários modos (KOORSGARD, 2011, p. 668). Salienta Bachur (2016, p.6) que "a substituição do termo ator por actante pretende, a um só tempo, eliminar a pré-compreensão de uma racionalidade subjetiva que age e destacar que só vale como actante o mediador ativo que realiza uma tradução".

A Tradução inclui quatro subprocessos distintos: problematização, interessement, inscrição ou registro e mobilização (CALLON, 1986):

a) Problematização: é uma etapa inicial na construção de uma rede. Iniciadores tentam impor a definição de um problema e sua solução. Iniciadores não só definem os problemas e as soluções, mas também estabelecem papéis e identidades de outros atores na rede. Através de problematização, iniciadores estabelecem um "ponto de passagem obrigatório" (GHERARDI; NICOLINI, 2005, p. 289) de solução de problema. Dito de outro modo, problematização é quando um conjunto inicial de atores define (ou redefine) um problema e se oferece como uma solução. O objetivo é fazer com que a nova definição seja reconhecível para os outros, tornando a sua aceitação de um ponto de passagem obrigatório para entrar na rede, e tornando-se indispensável no processo (GHERARDI; NICOLINI, 2005). Como o artefato é moldado por atores, os quais o assumem de acordo com seus interesses, eles modificam, transformam e deslocam ou descartam, traduzem-no. Por isso, o processo de tradução envolve o estabelecimento de um ponto de passagem (PORSANDER, 2005);

b) Interessement engloba uma variedade de estratégias e mecanismos pelos quais os iniciadores tentam registrar outras entidades. Interessement é o processo pelo qual as interrelações são investidas por algum interesse. Ele sempre começa com uma manobra de interrupção, o que elimina problematizações alternativas e inscrições. Uma vez que as relações tenham sido especificadas, um padrão de troca emerge e estabelece o que cada uma das entidades vai receber em troca por envolver-se na rede. Callon (1986) observou que interessement bem-sucedida confirma a validade da problematização e as alianças na rede;

c) A inscrição ou registro é um conjunto de estratégias em que iniciadores procuram convencer outros atores a se juntarem a eles em um processo político multilateral (CALLON apud HÖLMSTRÖM; ROBEY, 2005). Descrever a inscrição é descrever o grupo de negociações multilaterais, provas de força e truques que acompanham os interessements. Cada inscrição envolve sempre algum tipo de negociação e ele passa por tentativa e erro (GHERARDI; NICOLINI, 2005);

d) A mobilização é um conjunto de métodos que iniciadores usam para garantir que os porta-vozes aliados representem seus eleitores corretamente e não traiam os interesses dos iniciadores. Com aliados mobilizados, um ator-rede alcança estabilidade e a rede passa a 
operar como um "ator" reconhecível e pode produzir algum efeito no mundo por meio de seus intermediários (GHERARDI; NICOLINI, 2005, p. 290).

Com isso, o processo do surgimento de um ator-rede é resultante de: 1) introdução de um ponto de passagem obrigatória a ser ultrapassado, ou seja, um ponto que precisa ser atravessado por atores a fim de obterem seus interesses; 2) formação de um pacto: um actante tenta bloquear outros actantes em suas funções apropriadas e, assim, formar uma base de poder para si mesmo; 3 ) realização de várias negociações, com a utilização de diferentes tipos de estratégias nos quais um actante define-se atuante e inter-relaciona várias funções atribuídas aos outros; 4) encontro de um porta-voz: uma vez que a rede foi formada, é necessário decidir quem vai falar por ela, fortalecendo a ilusão de um único ator (CALLON apud PORSANDER, 2005). Contudo, esse processo não implica na noção de fases e trajetórias, que é rejeitada por Latour (KORSGAARD, 2011), mas resulta em "cadeias de associações entre um volume de actantes (humanos e não humanos) que participam da construção de uma situação específica" (PRIMO, 2014, p. 519), em um processo indeterminado, contínuo e não linear (KORSGAARD, 2011).

Gherardi e Nicolini (2005) salientam que a TAR procura descrever estratégias, manobras e ações com as quais atores coletivos realizam traduções, a fim de consolidarem a rede que os suporta e torná-la permanente sempre que possível. Contudo, é importante salientar que uma rede exige constante mobilização para ser mantida, pois redes são essencialmente instáveis e contingentes (BACHUR, 2016). Nesse sentido, esta pesquisa realizada junto a Associações de Mulheres de Negócios procurou descrever a formação dessas redes, como sugerem Hoskisson et al. (2011), por meio de estratégias e ações utilizadas para produzir traduções.

\section{PROCEDIMENTOS METODOLÓGICOS}

A TAR insere-se no domínio dos estudos normativos pós-estruturalistas. Enquadra-se como relativista, na medida em que reivindicações estão sempre em mudança e que humanos e não humanos estão sempre em interações relativas uns com outros.O técnico e o social se coproduzem e juntos podem ser compreendidos na forma de uma rede, sendo sempre fenômenos "relacionais e contextuais", que continuamente "se fazem e refazem"( HASSARD; COX, 2013, p. 1711). Como as relações precisam se desempenhar repetidamente e as networks não se dissolvem, a abordagem caracteriza-se pelo relacionismo (HASSARD; COX , 2013).

Nesta pesquisa, buscou-se compreender a formação de redes de empreendedoras, especificamente Associações de Mulheres Empresárias, inseridas em Associações Comerciais. O estudo foi realizado em Associações de Mulheres, que tiveram início nas décadas de 1980 e 1990. Duas delas estão localizadas no Estado do Paraná e outra no Estado de Santa Catarina. A escolha foi resultante de acessibilidade e equivalência das redes em termos contextuais, considerando que todas se inseriam em Associações Comerciais. Tendo em vista a questão da confidencialidade, os dados foram apresentados sob a denominação de associações A, B e C.

A coleta de dados ocorreu de forma transversal, delineando-se a trajetória das Associações e de processos constitutivos das redes por meio de dados primários e secundários. Quanto aos dados secundários, estes foram obtidos por meio de análise documental, utilizando-se livros-atas das reuniões, além de clippings e materiais de divulgação e vídeos institucionais, reportagens de jornais e revistas constantes no arquivo das Associações. A coleta de dados, que foi viabilizada pela consulta aos arquivos de cada Associação, abrangeu o período da fundação das Associações, sendo 1985, 1986 e 1996. 
Os dados primários foram obtidos por meio de entrevistas abertas, do tipo narrativas, nas quais cada empreendedora narrava a formação da rede à qual pertencia. Buscou-se identificar nas narrativas os fluxos de ações em que cada participante foi tratado como mediador, e como a rede de atores produziu um conjunto de relações definidas como traduções (BACHUR, 2016). Os sujeitos da pesquisa foram mulheres empreendedoras que participaram da constituição das associações, identificadas com o apoio das associações. Foram entrevistadas 12 empreendedoras, número esse que propiciou a saturação dos dados. A fim de manter a confidencialidade dos dados, elas foram identificadas pelas siglas: MC, MT, EM, MF, LC, LT, LM, LL, FC, FT, FM e FL.

As entrevistas foram transcritas e, juntamente com os dados secundários, foram inseridas no software Nvivo 9, a fim de realizar a codificação em torno de unidades temáticas explicativas (BAUER, 2002). As unidades temáticas explicativas no texto (BAUER, 2002), tanto no conteúdo das entrevistas transcritas, como na pesquisa documental, foram definidas em torno das etapas da tradução. O material foi codificado com auxílio do software e foram geradas, inicialmente, duas categorias: início das associações de mulheres e tradução. A tradução, por sua vez, foi subcategorizada em três subcategorias - problematização; interessement e registro ou inscrição; e, mobilizações e negociações - criando um corpo e tornando-se macroatores. Para a análise dos dados procurou-se identificar as traduções representativas da atuação de empreendedoras na rede, identificando elementos humanos e não humanos, como sugere Latour (2008), tanto para os dados primários, como para os secundários.

\section{APRESENTAÇÃO E ANÁLISE DOS DADOS}

As Associações de Mulheres de Negócios, objeto desta pesquisa, fazem parte de Associações Comerciais, que são redes constituídas anteriormente nos municípios. Antes de abordar a formação das redes, ou seja, a conversão de muitos em uma unidade (LATOUR, 2008), apresenta-se uma descrição sucinta referente ao início das atividades.

\subsection{Início das Associações de Mulheres}

De acordo com a pesquisa documental, no caso das associações paranaenses, o programa Ação Empresarial, patrocinado pela Confederação das Associações Comerciais do Brasil e orientado pela Associação Comercial do Paraná, instalou-se em Curitiba e pretendia se interiorizar. O movimento de criação de conselhos de mulheres nas Associações do país teve origem com o I Encontro Nacional da Mulher Executiva, realizado em 1983 no Rio de Janeiro, na sede da Associação Comercial. Conforme registros no arquivo de uma das Associações, o Presidente daquela Associação Comercial ressaltou a importância da participação da mulher na busca de soluções para os problemas essenciais que afetavam o país naquele momento. A Confederação das Associações Comerciais do Brasil criou então a Ação Empresarial, movimento que se propagou nas mais de 100 Associações Comerciais do Brasil, nas Federações Estaduais e na Confederação Nacional das Associações, mediante rápida convocação e cada uma, de forma individual, mas todos simultaneamente.

Em maio de 1985, na Associação A a presidente do Conselho Permanente da Mulher executiva do Estado foi falar sobre o Conselho da Mulher Executiva que vinha sendo implantado em todo o país, nas Associações Comerciais. Na Associação B, desde 1980, as mulheres ocupavam cargos na diretoria da Associação Comercial e, em 30 de abril de 1985, o 
Conselho da Mulher foi criado naquela cidade. No caso de B, juntamente com a criação do Conselho, foi simultaneamente aprovado o seu Estatuto (em 5 de setembro de 1985).

A criação da Associação A recebeu a denominação de Conselho da Mulher Executiva e contou com a presença de 28 mulheres na primeira reunião. No entanto, posteriormente, foi ocorrendo esvaziamento e, na segunda reunião, segundo uma das entrevistadas, somente 15 mulheres participaram. Na terceira reunião a participação foi reduzida para oito e para quatro nas reuniões subsequentes. Na Associação B, o Conselho foi criado com apenas cinco empresárias, sendo uma delas a presidente. Esta também encontrou dificuldades para obter adesões.

No outro Estado, a implementação da rede ocorreu mais tarde, sendo que C teve início em 21 de junho de 1996, mas, embora tenha sido criado formalmente, o conselho praticamente não atuou, principalmente devido à dificuldade em obter adesões. Segundo uma das entrevistadas, as iniciantes realizavam diversos contatos telefônicos com outras mulheres, para obter adesões. Outra estratégia foi a de reduzir o quórum mínimo de 20 para cinco participantes. Mesmo assim, segundo uma das entrevistadas, a presença nas reuniões era muito pequena e as iniciantes enviavam correspondências para as faltantes, com a mensagem: "Sentimos sua falta!", a fim de sensibilizá-las a comparecerem nas próximas reuniões. Esses esforços não resultaram em um processo de tradução e o grupo não foi adiante. Um novo grupo assumiu em 1997, composto por quatro empresárias, que criaram a Câmara da Mulher Empresária de C, como mostram os trechos:

$\mathrm{Na}$ época, houve uma palestra, e nessa palestra o presidente da Associação Comercial se apresentou e disse que queria criar uma câmara, não sei se a outra não era muito ativa, também não tem muito registro do que fizeram ou não fizeram, se fizeram alguma coisa, e ele queria uma coisa bem atuante. A partir dessa palestra a gente se organizou e perguntou quem é que gostaria de participar, as empresárias que estavam ali fizeram parte e formaram o primeiro grupo. Aí nós criamos tudo, o que é que nós iríamos fazer, como é que nós iríamos fazer, nós tínhamos reuniões semanais ou quinzenais, e aí começamos a organizar cursos e várias atividades voltadas pra mulher (MC).

Foi um momento novo na Associação Comercial, quando eles começaram a abrir espaço para mulher. Era de uma forma ainda muito tímida, a gente não tinha privilégios, ... a gente se reuniu, eu já conhecia a N. da ADVB Mulher. E um dia chamaram a N. para iniciar esse trabalho, ela me convidou e eu fui nessa primeira reunião, e a gente então pegou essa bandeira da Associação Comercial ...... Na época, chamava câmara da mulher empresária. Éramos três a princípio, era eu, a $\mathrm{N}$ e a $\mathrm{H}$... Em seguida entrou a $\mathrm{C}$, que hoje vai ser a presidente, e nós quatro tocamos, fizemos um bom trabalho na época, eu era muito focada no associativismo, o projeto empreender estava recém começando aqui, também um projeto pioneiro no Brasil, porque ele veio da Alemanha, e eu estava muito engajada nisso, eu acreditava muito nisso e parecia que as pessoas acreditavam também, mas a gente não conseguia tocar a coisa pra adiante. Não chegou a ser um convite, foi um desafio que a Associação Comercial nos colocou (MT).

Nessa fase, a Câmara da Mulher Empresária C previa, para o período entre outubro de 1997 e junho de 1998, o seguinte:

reunir potencialidades empresariais femininas para o crescimento e desenvolvimento empresarial do município; estimular a participação das mulheres em eventos empresariais, sociais e culturais; fomentar o surgimento de novas lideranças femininas no mundo empresarial; servir como fator de integração entre a Associação, seus membros e a Comunidade; captar associadas junto à comunidade empresarial; contribuir, como um novo espaço, para o fortalecimento da Associação Comercial no seu âmbito de atuação. (Ata Associação C). 
Contudo, ainda em 1997, na presença do presidente da Associação Comercial, as participantes da Associação questionaram a não aceitação de mulheres na diretoria da Associação Comercial, mas o presidente da Associação Comercial não aceitou o questionamento e retirou-se da reunião. A presidente da Associação das Mulheres apresentou sua renúncia.

As três Associações de Mulheres foram formalmente introduzidas nas Associações Comerciais, sem que os interesses de participantes fossem avaliados ou que as mulheres fossem legítimas porta-vozes. Para Latour (2005) a construção da rede pelos atores resulta de legítimos porta-vozes (LATOUR, 2005). Face à pouca legitimidade, as mulheres procuraram redefinir relações e assegurar legitimidade de papéis, como será discutido a seguir.

\subsection{Tradução}

No âmbito da TAR, tradução (translation) "é o processo de negociação pelo qual os atores assumem a autoridade para agir e falar em nome de outros atores" (HERNES, 2005, p. 168). A translação refere-se ao movimento como as redes e as relações tornam-se estáveis (CAMILLIS; ANTONELLO, 2016), em um movimento lento de transposição de um lugar para outro (MATOS; IPIRANGA, 2017). Esse processo inclui três subprocessos distintos: problematização; interessement e registro ou inscrição; e, mobilização (CALLON, 1986).

\subsubsection{Problematização}

Hernes (2005) salienta que para a emergência de um ator-rede os iniciantes procuram definir um problema comum para todos os atores. Eles não apenas definem problemas e soluções, mas também estabelecem papéis para cada ator na rede.

Quanto às Associações, inicialmente a problematização foi construída sobre a falta de espaço físico, de uma sede ou um espaço apropriado para a rede. Na Associação A, com a falta de espaço físico, na primeira gestão, as atas eram levadas para a empresa da secretária. A loja sofreu um incêndio e, juntamente com outras coisas, as atas foram queimadas. Na Associação B, as reuniões eram realizadas na sala de reuniões gerais da Associação Comercial, tendo o espaço físico sido conquistado apenas na segunda gestão. A Associação C demorou oito anos para conseguir espaço físico.

O espaço físico foi o problema inicial, que precisava ser superado, a fim de garantir uma unidade que conferisse às mulheres maior poder e, ao mesmo tempo, representasse uma possibilidade de, enquanto coletividade de atores, terem projetos associados a seus interesses (CZARNIAWSKA; HERNES, 2005; LATOUR, 2008). A definição de projetos associados a seus interesses representava outra problemática, que foi sendo tecida em conjunto.

\subsubsection{Interessment e Registro ou Inscrição}

Interessement envolve a variedade de estratégias e mecanismos pelos quais os iniciadores tentam registrar outras entidades. Em um nível geral, interessement envolve ações por meio das quais uma entidade tenta impor e estabilizar sua identidade para outros atores (HERNES, 2005). Observou-se que um conjunto de estratégias e mecanismos foi utilizado pelas associações de mulheres. Uma das primeiras estratégias foi a formalização de atribuições, por meio de estatutos próprios. O estatuto, enquanto elemento não humano transforma-se em artefato na medida em que se associa aos anseios de legitimação das participantes das redes. Embora ele figure como elemento que pode atribuir poder às mulheres no âmbito da Associação Comercial, ele não isenta a agência das mulheres, na medida em que a atribuição de agência a objetos não anula intenções de humanos (PRIMO, 2014). Mas, 
como na TAR a agência não é privilégio de humanos, mas de redes de elementos humanos e não humanos (KORSGAARD, 2011), por meio do que configura no Estatuto, é conferido às mulheres alguma parcela de poder na rede para a realização do projeto comum.

Além disso, as feiras de negócios e rodadas de negociações foram elementos importantes na formação das redes. No caso da Associação das Mulheres de Negócios A a primeira feira foi a da Indústria, que além de servir como elo para canalizar a atividade de todas as conselheiras envolvidas na rede, foi aceita pela diretoria da Associação Comercial, servindo posteriormente como fonte de recursos financeiros. Esta foi importante, sobretudo para dar visibilidade inicial à rede. A primeira versão dessa Feira durou 10 dias e o trabalho de montagem e divulgação foi assumido pelas associadas. A visibilidade foi percebida quando as empresárias receberam uma correspondência do Ministério das Relações Exteriores da República, de Brasília, solicitando relação dos eventos do Conselho para publicação no calendário de feiras internacionais. A Feira representou um processo de mobilização e de empoderamento no âmbito da Associação Comercial. Na Feira, cada participante atuava como mediadora, por meio de um fluxo de ações abrangendo divulgação, estandes e comercialização. Para Bachur (2016) a rede é traçada por meio de fluxo de ações.

Ainda no Conselho A a Feira foi repetida, até a sua IV edição. Com a realização da IV Feira, em 1990 um superávit foi obtido e emprestado à Associação Comercial, favorecendo a legitimidade do Conselho junto à Associação. A Feira, enquanto projeto da rede, exerceu impacto na economia local, tendo sido um embrião de um Polo de indústrias de confecções que se instalou no município e que abrange aproximadamente 400 empresas. Em decorrência do Polo, foi então formado o Sindicato das Indústrias do Vestuário. Este último passou a ser parceiro da Associação de Mulheres para a realização da Feira, porém, posteriormente continuou a organizá-la, sem a participação do Conselho, transformando-a em Feira da Moda. A perda do projeto da Feira, que representava uma oportunidade para consolidar a rede e transformá-la em um projeto permanente, enquanto estratégia da rede, tal como sugerem Gherardi e Nicolini (2005), implicou na busca de novas ações, manobras e estratégias. O novo projeto eleito, por meio do qual muitas empreendedoras buscaram seus interesses, foi a Feira de Ponta de Estoques, copiada de visitas a outras cidades do Estado. Em abril de 1992, o Conselho lançou a Feira de Ponta de Estoques de A, que se transformou em projeto permanente. A Feira representava a formação de um pacto, por meio do qual as empreendedoras atuantes tentaram bloquear outros atuantes em suas funções apropriadas e, assim, formar uma base de poder para elas (PORSANDER, 2005). Essa base de poder foi apenas gradual, na medida em que, 11 anos após o surgimento do Conselho, as empresárias solicitaram à diretoria da Associação Comercial que tivessem direito a voto na diretoria geral da Associação Comercial, mas o assunto não foi levado em consideração. Após 1998 prosseguiu a dinâmica de construção da rede pelas empreendedoras, por meio de novos projetos, capazes de atribuir funções a todas e elas implementaram novos projetos, como visitas técnicas, mostras de produtos e projetos de capacitação profissional.

Para a Associação B, cinco anos após a sua criação, as empreendedoras organizaram a Feira "L. é Moda", um evento que posteriormente foi editado por quatro anos sob a denominação "Estação Fashion L.". Por meio desse projeto, observou-se a agência da rede, tendo a Feira sido divulgada em mídia nacional. Para a Associação se configurar como uma rede e as empreendedoras como macroatores, elas precisariam manifestar identidades relativamente estáveis, associadas a seus interesses particulares (FELDMAN; PENTLAN, 2005), o que foi buscado por meio da realização da Feira. Porém, esse projeto da Feira foi interrompido pela decisão de realizar as duas últimas versões em conjunto com o Shopping Center local, o que enfraqueceu a Feira, que foi desativada, sendo reativada somente no ano de 2003. 
Quanto à Associação $\mathrm{C}$, no início não há registro de Feiras, mas, um ano depois da constituição da rede, foi introduzido o projeto de rodadas e círculo de ideias. Outra estratégia foi a rodada de negócios, com a apresentação de algumas empresas das associadas. Somente 12 anos após a criação da Associação é que o projeto de Feiras foi implementado, tendo sido criadas a Feira de Antiguidades e a Feira de Negócios, bem como a Vitrine de Negócios e o Mercado das Pulgas. Nessa Associação, desde o começo das atividades, foram realizados churrascos para arrecadação de fundos e para integração das participantes, caracterizando um "processo não linear, de criação e recriação de artefatos" (KOORSGAARD, 2011, p. 662).

Para a TAR a emergência do social deriva de associações entre humanos e não humanos (LEMOS, 2014). No caso das três Associações, a associação entre humanos e não humanos pode ser observada entre elas e as feiras, ou seja, as feiras, sem elas, não teriam o sentido que tiveram e, para elas, as feiras possibilitaram o papel de actantes, agindo sobre outros ou sobre elas mesmas (CZARNIAWSKA, HERNES, 2005). No entanto, para actantes transformarem-se em atores, eles precisam adquirir relevância política estável (CZARNIAWSKA; HERNES, 2005), por meio da composição sucessiva de programas que definem novos padrões institucionais ou antiprogramas que resistem aos novos padrões. No caso das Associações A e B, as feiras estavam se transformando em padrões institucionais, mas outras instituições assumiram esses programas (O Sindicato e o Shopping Center). A estabilização da rede prescinde de práticas materiais reiteradas e de um certo número de actantes (BACHUR, 2016). Com isso, as mulheres, além das feiras, utilizaram outros elementos para conquistar relevância política estável. Foi o caso, por exemplo, de jantares e cafés. As Associações A e B introduziram os cafés da manhã, com a finalidade de "arrecadar fundos e aumentar o entrosamento entre as associadas" (LC), como comentou uma das entrevistadas. Isso foi importante, pois para networks não se dissolverem elas necessitam de "repetidamente desempenhar suas relações" (HASSARD; COX, 2013, p. 1711). Com esse propósito, promoveram ainda palestras e cursos rápidos relacionados a temáticas de gestão de suas empresas.

Por vezes, embora elas procurassem definir programas e construir artefatos, elas enfrentavam controvérsias com as Associações Comerciais, que limitavam a ação e a agência distribuída. Um exemplo ocorreu com a Associação C, que uma década após sua criação, lançou um projeto para a construção de um espaço para Casa do Papai Noel no município, mas a Diretoria Geral da Associação Comercial impediu a concretização do projeto. Segundo Callon (1986) alianças são importantes para um registro bem-sucedido, mas as empreendedoras encontraram dificuldades para realizar alianças no âmbito interno das próprias Associações Comerciais.

As Associações das Mulheres oscilaram entre momentos de avanços e de encolhimento no âmbito das Associações Comerciais, a fim de construírem suas identidades, tendo sido submetidas a controvérsias, que provocaram desânimos. Por exemplo, tanto a primeira quanto a segunda presidente da Associação B, em determinados momentos, cansaram e pensaram em desistir, mas visitaram Associações em outros municípios no Estado e voltaram com ideias diferentes. O desânimo afetou ainda as poucas conselheiras que participavam, sendo que elas realizaram apenas duas reuniões anuais em 1999, 2000 e 2001. Também na Associação A as empreendedoras pensaram em desistir.

Estratégias são traçadas por atores para tornarem as redes permanentes (GHERARDI; NICOLINI, 2005). Nas associações em estudo, a realização de Feiras, Jantares, Palestras, além de eventos festivos, tais como a Semana do Meio Ambiente, o Dia das Mães, o Dia Internacional da Mulher, a Páscoa e o Natal, foram estratégias para tornar as redes permanentes, representando um conjunto de estratégias por meio das quais as iniciadoras buscaram convencer outras mulheres a se juntarem a elas, em um processo político multilateral (CALLON, 1986). 


\subsubsection{Mobilização e Negociações}

Mobilização é um "conjunto de métodos que iniciadores usam para garantir que os porta-vozes aliados representem seus eleitores corretamente e não traiam os interesses dos iniciadores. Com aliados mobilizados, uma rede ator alcança estabilidade" (HOLMSTRÖM; ROBEY, 2005, p. 168). Na mobilização, os participantes buscam convencer os outros a desempenhar os papéis (CAMILLIS; ANTONELLO, 2016). Negociações e parcerias ocorreram nas Associações. As associações B e C realizaram parcerias com a BPW Business Professional Women - outra rede internacional de mulheres (BPW, 2006). Em C, a aproximação com a rede BPW ocorreu inicialmente por meio de uma palestra em parceria, no ano de 2006. Posteriormente, a Câmara da Mulher Empresária tornou-se parceira da BPW na realização de cursos, palestras, eventos destinados a mulheres empresárias da região e, no final de março, a coordenadora da Câmara da Mulher assumiu a primeira vice-presidência da BPW, acumulando os cargos. A adesão a outra rede similar ocorreu como estratégia para a estabilização da rede porque os interesses das mulheres não foram conquistados nas Associações Comerciais.

De outra forma, as negociações da Associação A não ocorreram com a BPW, mas com outras entidades do município, por meio da participação e representatividade das conselheiras em organizações locais, como na Câmara da Mulher no Conselho Comunitário de Segurança do município. Além disso, elas passaram a atuar em projetos coordenados por outros setores, como o Censo Econômico para o perfil da mulher no município, os projetos de saúde da mulher, e a parceria com uma cooperativa local para formatação de programa Formação de Gênero, dentre outros.

O planejamento estratégico foi implementado a partir de 1998, na Associação C, para garantir a representação na Associação Comercial. Em 1999, o planejamento foi delineado com suporte de consultor externo, também consultor da Associação Comercial, tendo sido institucionalizado na rede após esse período. No caso de B, o planejamento foi realizado em conjunto com o Serviço Brasileiro de Apoio à Micro e Pequena Empresa-SEBRAE. Em A, uma consultoria externa forneceu orientações para o plano estratégico, pautado nas seguintes linhas: Estruturação da Comunicação e do Marketing do Conselho da Mulher; Desenvolvimento de Lideranças Femininas; Reestruturação do Conselho da Mulher; Fortalecimento do Conselho da Mulher Empresária; e, Desenvolvimento de Produtos e Serviços voltados para mulher empresária.

\subsubsection{Criando um corpo e tornando-se macroatores}

A transformação em macroatores implica em identidades relativamente estáveis, refletidas pelo fato de que "alguns falam em nome de outros" (HELGESSON; KJELLBERG, 2005). Essa transformação assumiu contornos diferenciados em cada um dos casos. Na Associação A, com a participação desta em redes externas, ampliou-se a mobilização externa. Apesar disso, internamente a mobilização era reduzida, na medida em que as participantes representavam apenas um voto na Diretoria Geral da Associação Comercial. Na Associação B, a criação de um corpo continuava sendo buscada, por meio da tentativa de retomar projetos anteriores. A Associação $C$ estava projetando a definição de um plano para contemplar a divulgação dos empreendimentos das participantes. Nos três casos a mobilização para a criação de um corpo que representasse o "ator-rede" constituíram processos "não lineares e descontínuos" (KORSGAARD, 2011, p. 662).

Essas redes não se concretizaram ainda enquanto atores-redes, pois mesmo tendo assumido uma série de Programas, elas continuam em busca de legitimação, que é importante para atores em redes (CZARNIAWSKA, 2008, 2009). Elas alcançaram apenas visibilidade externa, na medida em que internamente, no âmbito das Associações Comerciais, elas não 
conseguem representatividade paritária nas diretorias, como pode ser observado no trecho a seguir:

\begin{abstract}
Não deveria existir o Conselho da Mulher Empresária, que deveria ter um monte de mulheres no Conselho de Administração, entende? Lutando por benefício, direitos, por vantagens, por melhoria para todos os empresários....Então a gente precisa sim estar dentro do Conselho da Mulher para fazer valer a nossa visão, a nossa posição, para ter valorização, para mostrar que somos competentes tanto quanto, mas já pensando que daqui há pouco não precisa ter mais o conselho da mulher, que a gente tenha liderança suficiente para estar presente, e quem sabe ser... ter uma mulher na presidência da Associação Comercial (EM).
\end{abstract}

A relativa figuração que as participantes dessas redes conquistaram evidencia que as participantes são ainda actantes, pois para Latour (2008, p. 106) "tudo o que pode mudar, com a sua própria existência, um estado de coisas ou uma relação entre outras coisas, é um ator ou, e, se ele não tem qualquer figuração, é um actante." Para refletir a imagem de uma unidade, com maior poder a todos actantes envolvidos poder por meio de suas associações (LATOUR, 2005) as Associações de mulheres precisam maior empoderamento no âmbito das Associações Comerciais.

As relações tecidas no âmbito dessas associações, foram derivadas de composições e conferiram formas sempre provisórias (ESCÓSSIA; KASTRUP, 2005). Redes são "essencialmente instáveis e contingentes" (BACHUR, 2016, p. 6) e para a TAR é a associação entre humanos e não humanos, reiterada pelas práticas materiais da vida cotidiana que determina as redes.

\title{
5 CONSIDERAÇÕES FINAIS
}

A análise de como emergiram as Associações de Mulheres de Negócios nos contextos estudados, a partir da TAR, mostrou trajetórias percorridas, em processos de tradução, nos quais elementos humanos e não humanos formataram essas redes, em busca de uma unidade (LATOUR, 2008). Enquanto coletividade de atores, as empreendedoras precisavam ter projetos associados a seus interesses (CZARNIAWSKA; HERNES, 2005; LATOUR, 2008) e a construção das redes figurou como tentativa constante de legitimação de projetos, evidenciando a importância da soma das mobilizações rumo ao processo de tentativa de construção de macroatores. Uma dinâmica de tensões e ajustes foi observada.

A pouca legitimidade interna dessas redes, no âmbito das Associações Comerciais, enquanto condição necessária para transformação em atores redes foi notada mesmo após uma década de terem sido formalmente constituídas. O processo se apresentou de modo não linear, permeado por resistências, por parte das Associações Comerciais, à legitimidade das redes.

Embora haja críticas à abordagem da TAR em torno do caráter conservador, acrítico e da negação da influência de aspectos psicológicos, a abordagem TAR, nesta pesquisa forneceu elementos para compreender a dinâmica de construção de atores rede, enquanto um processo contínuo de busca de agência distribuída e de transformação de muitos em uma unidade, frutos da interação entre elementos humanos e não humanos.

Esta pesquisa mostrou estratégias e ações utilizadas para produzir traduções e para buscar consolidar redes, preenchendo lacuna apontada anteriormente por Hoskisson et al. (2011). É importante destacar dois aspectos dos casos estudados. O primeiro refere-se ao estabelecimento de uma rede no âmbito de outra rede existente (Associação Comercial). O segundo refere-se ao fato de serem as redes, exclusivamente, de homens (Associação Comercial) e, exclusivamente, de mulheres (Associação das mulheres). Estudos futuros 
poderão ser realizados sobre a formação de redes em contextos independentes e heterogêneos do ponto de vista de gênero.

Por fim, destaca-se que uma das limitações desta pesquisa foi a de analisar a formação das redes a posteriori, a partir de narrativas de participantes e de documentação histórica. Etnometodologias tornariam possíveis a análise do processo de constituição de atores rede, a partir da dinâmica performativa da ação, evidenciando melhor a dinâmica de inter-relações e de interesses. 


\section{REFERÊNCIAS}

ALCADIPANI, R; TURETA, C. Teoria Ator-Rede e análise organizacional: contribuições e possibilidades de pesquisa no Brasil. Organização \& Sociedade, Salvador, v. 16, n.51, p. 647-664, out./dez. 2009.

ALCADIPANI, R.; HASSARD, J. Actor-network theory, organization and critique: Towards a politics of organizing. Organization, Thousand Oaks, v.17, p. 419-435, may 2010.

AHL, H. The scientific reproduction of gender inequality. Herndon: Copenhagen Business School Press, 2004.

BACHUR, J.P. Assimetrias da Antropologia Simétrica de Bruno Latour. Revista RBCS, São Paulo, v. 31, n. 92, p. 1-21, out. 2016.

BAUER M. Análise de conteúdo clássica: uma revisão. In: BAUER, M.; GASKELL, G. (Org.). Pesquisa qualitativa com texto, imagem e som. Um manual prático. Petrópolis: Vozes, 2002. p. 189-217.

BPW - Business professional women. Disponível em: <http://www.bpwbrasil.org.br/quemsomos.asp>. Acesso em 17 abr. 2006.

CAIAFA, J. Dinâmicas da experiência de automação integral da condução do metrô de Paris. Contemporânea Comunicação e Cultura, Salvador, v. 12, n. 3, p. 595-613, set./dez. 2014.

CALLON, M. Some elements of a sociology of translation: domestication of the scallops and the fishermen of St. Brieuc Bay. In: LAW, J. (Org.). Power, action and belief: a new sociology of knowledge. London: Routledge, 1986. p. 196-223.

CARTER, S. Women business ownership: a review of the academic, popular and internet literature. Report to the Small Business Service. Glasgow: University of Strathclyde, 2001.

COSTA, S. A; MORGAN, B. F. Contribuição da Teoria Ator-rede para compreensão do paradoxo da gestão estratégica de custos. Advances in Scientific and Applied Accounting, São Paulo, v. 10, n. 2, p. 132-152, maio/ago. 2017.

CZARNIAWSKA, B., HERNES, T. Actor-network theory and organizing. Copenhagen: Liber \& Copenhagen Business School Press, 2005.

CZARNIAWSKA, B. Emerging institutions: pyramids or anthills? Organization Studies, Thousand Oaks, v. 30, n.4, p. 423-441, apr. 2009.

CZARNIAWSKA, B. How to misuse institutions and get away with it: some reflections on institutional theory(ies). In: GREENWOOD, R. et al. The Sage Handbook of Organizational Institutionalism. London: Sage, 2008. p. 769-782.

CAMILliS, P. K.; ANTONELLO, C. S. Da translação para o enactar: contribuições da Teoria Ator-Rede para a abordagem processual das organizações. Cadernos EBAPE, Rio de Janeiro, v. 14, n. 1, p. 61-82, jan./mar. 2016. 
DOWNING, S. The social construction of entrepreneurship: narrative and dramatic processes in the coproduction of organizations and identities. Entrepreneurship Theory and Practice, Singapore, v. 29, n. 2, p. 185-204, mar. 2005.

ESCÓSSIA, L., KASTRUP, V. O conceito de coletivo como superação da dicotomia indivíduo sociedade. Psicologia em Estudo, Maringá, v. 10, n.2, p. 295-304, maio/ago. 2005.

FELDMAN, M.; PENTLAND, B. Organizational routines and the macro-actor. In: CZARNIAWSKA, B.; HERNES, T. Actor-network theory and organizing. Copenhagen: Liber \& Copenhagen Business School Press, 2005.

GHERARDI, S.; NICOLINI, D. Actor-networks: ecology and entrepreneurs. In: CZARNIAWSKA, B.; HERNES, T. Actor-network theory and organizing. Copenhagen: Liber \& Copenhagen Business School Press, 2005. p. 285-306.

HASSARD, J.; COX, J.W. Can sociological paradigms still inform organizational analysis? A paradigm model for post-paradigm times. Organizational Studies, Thousand Oaks, v. 34, n. 11, p. 1701-1728, nov. 2013.

HELGESSON, C.; KJELLBERG, H. Macro-actos and the sounds of the silenced. In: CZARNIAWSKA, B.; HERNES, T. Actor-network theory and organizing. Copenhagen: Liber \& Copenhagen Business School Press, 2005.

HERNES, T. The organization as nexus of institutional macro actors: the story of a lopsided recruitment case. In: CZARNIAWSKA, B.; HERNES, T. Actor-network theory and organizing. Copenhagen: Liber \& Copenhagen Business School Press, 2005.

HOLMSTRÖM, J.; ROBEY, D. Inscribing organizational change with information technology. In: CZARNIAWSKA, B.; HERNES, T. Actor-network theory and organizing. Copenhagen: Liber \& Copenhagen Business School Press, 2005.

HOSKISSON, R. et al. Revitalizing entrepreneurship: the search for new research opportunities. Journal of Management Studies, Singapore, v. 48, n.6, p. 1141-1168, sept. 2011.

KORSGAARD, S. Entrepreneurship as translation: understanding entrepreneurial opportunities through actor-network theory. Entrepreneurship \& Regional Development, Abingdon, v. 23, n. 7-8, p. 661-680, oct. 2011.

LATOUR, B. La science em action introduction à la sociologie des sciences. Paris: Découverte, 2005.

LATOUR, B. Reensamblar lo social - uma introducción a la teoría del actor-red. Buenos Aires: Manantial, 2008.

LEMOS, A. Editorial. Contemporânea, comunicação e cultura, Salvador, v. 12, n. 3, p. 476-477, set./dez. 2014.

LOPES, I. F.; BEUREN, I. Análise das Publicações internacionais de contabilidade gerencial sob a lente da teoria Ator-Rede. Advances in Scientific and Applied Accounting, São Paulo, v.10, n.2, p. 189-210, maio/ago. 2017. 
MACHADO, H. V.; JESUS, M. F. Efeitos da participação de mulheres em redes sociais: um estudo em um conselho de mulheres executivas. Revista Economia \& Gestão, Belo Horizonte, v. 10, n. 24, p. 9-27. set/dez. 2010.

MANOLOVA, T. S. et al. The differential effect of men and women entrepreneurs' human capital and networking on growth expectancies in Bulgaria. Entrepreneurship Theory and Practice, Singapore, v. 31, n. 3, p. 407-426, may 2007.

MATOS, L. B. S.; IPIRANGA, A. S. R. The translations and the organizing of scientific practices in R\&D biotechnology. Revista de Administração, São Paulo, v.52, n. 2, p. 199211, abr./jun. 2017.

MÉLLO, R. P.; SPINK, M. J.; MENEGON, V. M. Redes em conexão com a teoria Ator-Rede na psicologia no Brasil. Psicologia \& Sociedade, Belo Horizonte, v. 28, n. 3, p. 423-432, set./dez. 2016.

MONTENEGRO, L. M; BULGACOV, S. Reflections on actor-network theory, governance networks and strategic outcomes. Brazilian Administration Review, Rio de Janeiro, v. 11, n.1, p. 107-124, jan./mar. 2014.

MOURITSEN, J.; FLAGSTAD, K. The making of knowledge society: intellectual capital and paradoxes of managing knowledge. In: CZARNIAWSKA, B.; HERNES, T. Actor-network theory and organizing. Copenhagen: Liber \& Copenhagen Business School Press, 2005.

PORSANDER, L. May name is lifebuoy. An actor-network emerging from on action-net". In CZARNIAWSKA, B.; HERNES, T. Actor-network theory and organizing. Copenhagen: Liber \& Copenhagen Business School Press, 2005.

PRIMO, A. F. T. Como fala uma actante coletivo? A organização FIFA encomendada por Jerôme Valcke. Contemporânea, Comunicação e Cultura, Salvador, v. 12, n.3, p. 512-536, set./dez. 2014.

TONELLI, D. F. Origens e afiliações epistemológicas da teoria Ator-Rede: implicações para a análise organizacional. Cadernos EBAPE, Rio de Janeiro, v. 14, n. 2, p. 377-390, abr./jun. 2016.

TONELLI, D. F; BRITO, M. J.; ZAMBALDE, A. L. Empreendedorismo na ótica da teoria Ator-Rede: explorando alternativa às perspectivas subjetivista e objetivista. Cadernos EBAPE, Rio de Janeiro, v. 9, p. 586-603, jul. 2011. 